Revista Brasileira de Agricultura Irrigada v.9, nº.6, p.366 - 375, 2015

ISSN 1982-7679 (On-line)

Fortaleza, CE, INOVAGRI - http://www.inovagri.org.br

DOI: $10.7127 /$ rbai.v9n600303

Protocolo 303.15 - 05/06/2015 Aprovado em 03/11/2015

\title{
DESEMPENHO DE GOTEJADORES AUTOCOMPENSANTES SUBMETIDOS A SOLUÇÕES CONCENTRADAS DE FERRO E CARGA ORGÂNICA
}

\author{
Lilian Cristina Castro de Carvalho ${ }^{1,}$ Rubens Duarte Coelho ${ }^{2}$, Marconi Batista Teixeira ${ }^{3}$, \\ Frederico Antonio Loureiro Soares ${ }^{4}$, Fernando Nobre Cunha ${ }^{5}$, Nelmício Furtado da Silva ${ }^{6}$
}

\section{RESUMO}

Objetivou-se com este experimento avaliar a vazão, o coeficiente de uniformidade de distribuição e o coeficiente de variação de vazão de diferentes tubos gotejadores autocompensantes submetidos a soluções com diferentes concentrações de ferro solúvel na água de irrigação. A pesquisa foi conduzida no Laboratório de Irrigação da Escola Superior de Agricultura "Luiz de Queiroz" - ESALQ/USP, localizada no município de Piracicaba - SP. Os tratamentos realizados podem ser resumidos da seguinte forma; fase $1=6 \mathrm{mg} \mathrm{L}^{-1}$ de $\mathrm{Fe}^{+2}$ (óxido de ferro) + carga orgânica (água LAG); na fase $2=18,8 \mathrm{mg} \mathrm{L}^{-1} \mathrm{de} \mathrm{Fe}^{+2}$ (sulfato ferroso, óxido de ferro e hidróxido de ferro) + sólidos suspensos (solo - $409 \mathrm{mg} \mathrm{L}^{-1}$ ) + carga orgânica com os emissores posicionados para cima. Depois de tabulados os dados, procederam-se os cálculos da vazão, coeficiente de uniformidade de distribuição e do coeficiente de variação de vazão. A uniformidade de aplicação foi afetada pela aplicação $\mathrm{Fe}^{+2}$ causando alterações de forma gradativa, as quais tendem aumentar com o tempo de aplicação.

Palavras-chave: orificio, qualidade da água, entupimento.

\section{UNIFORMITY AUTO COMPENSATING DRIPPERS SUBJECTED TO APPLICATION OF A CONCENTRATED SOLUTION OF IRON AND ORGANIC \\ LOAD}

\footnotetext{
${ }^{1}$ Professora do Instituto Federal do Ceará, IFCE. Av. Dr. Guarani, 317, Derby Clube, 62042-030, Sobral, CE. email: liliancarv@ifce.edu.br.

2 Eng. Agrônomo, Prof. Livre Docente, DER - Departamento de Engenharia Rural, Escola Superior de Agricultura Luiz de Queiroz, Universidade de São Paulo, Piracicaba, SP, C.P.: 9, CEP: 13418-900, fone (0xx19) 3447-8551, email: rdcoelho@esalq.usp.br

3 Eng. Agrônomo, Prof. Dr. Instituto Federal Goiano - IFGoiano - Rio Verde, GO, email: marconibt@gmail.com

4 Eng. Agrônomo, Prof. Dr. Instituto Federal Goiano - IFGoiano - Rio Verde, GO, email: fredalsoares@gmail.com

${ }^{5}$ Eng. Agrônomo, Doutorando em Ciências Agrárias - Agronomia, IFGoiano - Campus Rio Verde, Rio Verde, GO, email: fernandonobrecunha@hotmail.com

${ }^{6}$ Eng. Agrônomo, Doutorando em Ciências Agrárias - Agronomia, IFGoiano - Campus Rio Verde, Rio Verde, GO, email: nelmiciofurtado@gmail.com
} 


\begin{abstract}
The objective of this experiment was to evaluate the flow, the distribution uniformity coefficient and flow coefficient of variation of different autocompensantes driplines undergo solutions with different concentrations of soluble iron in irrigation water. This research was conducted at the School Irrigation Irrigation Laboratory Agriculture "Luiz de Queiroz" ESALQ / USP, located in Piracicaba - SP. The treatments carried out can be summarized as follows in Step 1: $6 \mathrm{mg}^{-1}$ of $\mathrm{Fe}^{+2}$ (iron oxide) + organic load (LAG water); in step 2: $18.8 \mathrm{mg}$ $\mathrm{L}^{-1}$ of $\mathrm{Fe}^{+2}$ (ferrous sulfate, iron oxide and iron hydroxide) + suspended solids (soil - $409 \mathrm{mg}$ $\left.\mathrm{L}^{-1}\right)+$ organic load with the emitters positioned upward. After tabulated data, they proceeded to the calculations of the flow, distribution uniformity coefficient and flow coefficient of variation. The uniformity of application was affected by $\mathrm{Fe}^{+2}$ application causing changes gradually, which tend to increase with the time of application.
\end{abstract}

Keywords: hole, water quality, concentrated solution

\section{INTRODUÇÃO}

Um sistema de irrigação localizada bem manejado resulta na economia de água e energia. Entretanto, assume papel de suma importância para o sucesso do empreendimento a qualidade da água que será utilizada, pois a obstrução dos emissores é um dos maiores problemas associados com a operação de irrigação por gotejamento (COSTA et al., 2010).

Diversos tipos de gotejadores estão disponíveis no mercado, apresentando diferentes sensibilidades ao entupimento, fato que pode ser verificado em trabalhos realizados por Ribeiro et al. (2012) e Cunha et al. (2013). Esse inconveniente advém de causas biológicas, físicas e/ou químicas, ocorrendo todos conjuntamente quando se utilizam águas com elevados valores de ferro, bactéria e material orgânico (RAVINA et al., 1992).

Para Busato et al. (2010), o alto teor de ferro total presente na água representa risco severo ao entupimento de emissores. Segundo Martinko et al. (1997), o entupimento ocorre devido à ação bacteriana associada ao ferro, que ao ser oxidado da forma ferrosa $\left(\mathrm{Fe}^{2+}\right)$ para a forma férrica $\left(\mathrm{Fe}^{3+}\right)$, forma precipitados de hidróxido férrico $\left(\mathrm{Fe}(\mathrm{OH})_{3}\right)$ muito insolúveis em água.

A vazão média e o coeficiente de uniformidade de distribuição de emissores podem ser considerados bons parâmetros para avaliar o processo de entupimento, conforme utilizados por diversos pesquisadores (GILBERT et al., 1979; RAVINA et al., 1992; CAPRA, A.; SCICOLONE, 2004; COELHO et al., 2014).

Objetivou-se com este experimento avaliar a vazão, o coeficiente de uniformidade de distribuição e o coeficiente de variação de vazão de diferentes tubos gotejadores autocompensantes submetidos a soluções com diferentes concentrações de ferro solúvel na água de irrigação.

\section{MATERIAL E MÉTODOS}

A pesquisa foi conduzida no Laboratório de Irrigação de Irrigação da Escola Superior de Agricultura “Luiz de Queiroz” - ESALQ/USP.

$\mathrm{O}$ experimento foi desenvolvido em uma bancada de ensaios, construída em estrutura metálica composta por três andares, com $11 \mathrm{~m}$ de comprimento, $4 \mathrm{~m}$ de largura e 5,8 m de altura, sendo cada andar da bancada independente dos demais. Foi utilizado $10 \mathrm{~m}$ de cada modelo de tubo gotejador, conforme características citadas na Tabela 4.

Os andares foram divididos em duas partes, sendo cada uma composta por diferentes níveis para a inserção das linhas gotejadoras que foram unidas no início e no final da bancada por registros e conexões de PVC. Para a condução da água e montagem das linhas de gotejadores do ensaio utilizou-se 


\section{DESEMPENHO DE GOTEJADORES AUTOCOMPENSANTES SUBMETIDOS A SOLUÇÕES CONCENTRADAS DE FERRO E CARGA ORGÂNICA}

um registro de 2' na linha principal e um registro de 3/4' na entrada de cada nível. $\mathrm{Na}$ entrada de cada módulo da bancada, foi instalada uma tomada de pressão, permitindo o ajuste da pressão a cada medição de vazão, e se necessário, ajustada àquela preestabelecida. Para a medição e monitoramento da pressão de serviço, foi utilizado um manômetro com faixa de leitura de $0-700 \mathrm{kPa}$, calibrado previamente por um manômetro de peso morto.

O sistema de pressurização utilizado no experimento foi composto por um conjunto de motobomba centrífuga da marca KSB, modelo KSB Hydrobloc C 750, cuja o acionamento foi realizada manualmente. Para evitar a entrada de partículas em suspensão no sistema, foi utilizado um filtro de disco de 120 mesh/Amiad, com capacidade para $15 \mathrm{~m}^{3} \mathrm{~h}^{-1}$ de vazão, cuja limpeza foi feita a cada 12 horas de funcionamento.

No preparo e armazenamento das soluções utilizaram-se caixas de amianto, com capacidade para $1000 \mathrm{~L}$, que foram conectadas ao conjunto motobomba por meio de uma sucção de 0,06 m de diâmetro, através de um adaptador de caixa d'água e o bombeamento de cada solução foi controlado por um registro de esfera de 0,06 m, instalado na extremidade da sucção dentro da caixa, permitindo o bombeamento da solução. As soluções de ferro foram definidas conforme a tabela de classificação de água para irrigação por gotejamento proposta por Bucks et al. (1979).

O sistema de aplicação da solução foi adaptado de tal forma que permitia um processo de recirculação da mesma, onde a solução gotejada era recolhida por dois conjuntos de telhas de aço zincado (forradas com filme plástico), com uma inclinação de $3 \%$, aonde conduzia a solução para uma calha de zinco revestida com fibra de vidro, localizada no centro do modulo, que retornava a solução para a caixa da respectiva captação, através de um conjunto de tubos PVC de 100 mm.

Ao final da aplicação, os registros eram fechados com o sistema ainda em funcionamento, para evitar o retorno da solução ao reservatório, garantindo assim que a solução permanecesse em contato com toda a superfície interna da linha gotejadora. Para evitar uma perda acentuada da solução ao longo da semana, foram colocadas cortinas de plásticos nas laterais da bancada de ensaio, evitando evaporação. Após cada ensaio de vazão, o sistema permanecia desligado por um dia, com o objetivo de se fazer limpeza, preparo da nova solução, reparos e manutenção do sistema.

Os tratamentos realizados podem ser resumidos da seguinte forma; fase $1=6 \mathrm{mg} \mathrm{L}^{-1}$ de $\mathrm{Fe}^{+2}$ (óxido de ferro) + carga orgânica (água LAG) (Tabela 1).

Tabela 1. Análise da água do Laboratório de Irrigação da ESALQ/USP, que foi utilizada na preparação da solução aplicada na fase 1.

\begin{tabular}{lcc}
\hline \multicolumn{1}{c}{ Parâmetro } & Unidade & Resultado \\
\hline Alcalinidade $\left(2 \mathrm{CO}_{3}{ }^{2-}+\mathrm{HC}_{3}{ }^{-}\right)$ & $\mathrm{mg} \mathrm{L}^{1}$ & 35,8 \\
Cloreto $\left(\mathrm{Cl}^{-}\right)$ & $\mathrm{mg} \mathrm{L}^{1}$ & 33,9 \\
Nitrato $\left({\left.\mathrm{N}-\mathrm{NO}_{3}\right)}^{2-}\right.$ & $\mathrm{mg} \mathrm{L}^{1}$ & 20,5 \\
Sulfato $\left(\mathrm{SO}_{4}{ }^{2-}\right)$ & $\mathrm{mg} \mathrm{L}^{1}$ & 149,3 \\
Fósforo $(\mathrm{P})$ & $\mathrm{mg} \mathrm{L}^{1}$ & 0,05 \\
Nitrogênio Amoniacal $\left(\mathrm{N}-\mathrm{NH}_{3}\right)$ & $\mathrm{mg} \mathrm{L}^{1}$ & 0,11 \\
Sódio $\left(\mathrm{Na}^{+}\right)$ & $\mathrm{mg} \mathrm{L}^{1}$ & 44,0 \\
Potássio $\left(\mathrm{K}^{+}\right)$ & $\mathrm{mg} \mathrm{L}^{1}$ & 7,1 \\
Cálcio $\left(\mathrm{Ca}^{2+}\right)$ & $\mathrm{mg} \mathrm{L}^{1}$ & 33,2
\end{tabular}




$\begin{array}{lcc}\text { Magnésio }\left(\mathrm{Mg}^{2+}\right) & \mathrm{mg} \mathrm{L} & 9,2 \\ \text { Ferro }\left(\mathrm{Fe}^{2+}\right) & \mathrm{mg} \mathrm{L}^{1} & 0 \\ \text { Cobre }\left(\mathrm{Cu}^{2+}\right) & \mathrm{mg} \mathrm{L}^{1} & 0,01 \\ \text { Manganês }\left(\mathrm{Mn}^{2+}\right) & \mathrm{mg} \mathrm{L}^{1} & 0,09 \\ \text { Zinco }\left(\mathrm{Zn}^{2+}\right) & \mathrm{mg} \mathrm{L}^{1} & 1,14 \\ \text { Boro }(\mathrm{B}) & \mathrm{mg} \mathrm{L} & 0 \\ \text { Alumínio }\left(\mathrm{Al}^{3+}\right) & \mathrm{mg} \mathrm{L} & 0 \\ \text { Cor aparente } & \mathrm{PtCo}^{1} & 4 \\ \text { Turbidez } & \mathrm{FTU}^{3} & 4 \\ \text { Sedimentos em suspensão } & \mathrm{mg} \mathrm{L}^{1} & 6,0 \\ \text { Condutividade elétrica (CE) } & \mathrm{dS} \mathrm{m}{ }^{-1} & 0,37 \\ \text { pH } & ---- & 7,5 \\ \text { Gás carbônico }\left(\mathrm{CO}_{2}\right) & \mathrm{mg} \mathrm{L}^{1} & 1,9 \\ \text { Acidez }\left(\mathrm{CaCO}_{3}\right) & \mathrm{mg} \mathrm{L}^{1} & 6,5 \\ \text { Dureza total }\left(\mathrm{CaCO}_{3}\right)^{*} & \mathrm{mg} \mathrm{L}^{1} & 120,6\end{array}$

" Dureza total calculada com base no equivalente de carbonato de cálcio $\left(\mathrm{CaCO}_{3}\right)$.

$\mathrm{Na}$ Fase 2, os tratamentos permaneciam 24 horas em aplicação continua e 72 horas em repouso e avaliouse a susceptibilidade dos tubos gotejadores ao entupimento quando submetidos à aplicação de carga orgânica (fitoplâncton / algas), mais sólidos em suspensão, na concentração de $409 \mathrm{mg} \mathrm{L}^{-1}$ (Tabela 2) e $18,8 \mathrm{mg} \mathrm{L}^{-1}$ de ferro solúvel $\left(\mathrm{Fe}^{+2}\right)$, onde se utilizou como fonte de ferro uma associação de sulfato ferroso $\left(6 \mathrm{mg} \mathrm{L}^{-}\right.$ $\left.{ }^{1}\right)$, de óxido de ferro $\left(6 \mathrm{mg} \mathrm{L}^{-1}\right)$ e de hidróxido de ferro $\left(6,8 \mathrm{mg} \mathrm{L}^{-1}\right)$; associados apenas a água do lago e teve duração de 1068 horas de aplicação. Nesta fase (FASE 2), a linha gotejadora do setor 3 tiveram seus orifícios posicionados para baixo.

Tabela 2. Características físicas do solo utilizado na solução.

\begin{tabular}{|c|c|c|c|c|c|}
\hline \multicolumn{3}{|c|}{ Granulometria (\%) } & \multirow{3}{*}{$\begin{array}{c}\text { Classe Textural } \\
\text { argilosa }\end{array}$} & \multicolumn{2}{|c|}{ Densidade $\left(\mathrm{g} \mathrm{cm}^{-3}\right)$} \\
\hline argila & silte & areia & & global & partículas \\
\hline 48,16 & 17,72 & 34,12 & & 1,45 & 2,79 \\
\hline
\end{tabular}

Os tratamentos realizados na fase 2 pode ser resumido da seguinte forma: linhas gotejadoras do setor $3-18,8 \mathrm{mg} \mathrm{L}^{-1}$ de $\mathrm{Fe}^{+2}$ (sulfato ferroso, óxido de ferro e hidróxido de ferro) + sólidos suspensos (solo - $409 \mathrm{mg} \mathrm{L} \mathrm{L}^{-1}$ ) + carga orgânica (Tabela 3) com os emissores posicionados para cima (Tabela 3).

Tabela 3. Análise da água do lago utilizada na preparação da solução aplicada na fase 2

\begin{tabular}{lcc}
\hline \multicolumn{1}{c}{ Parâmetro } & Unidade & Resultado \\
\hline Alcalinidade $\left(2 \mathrm{CO}_{3}{ }^{2-}+\mathrm{HCO}_{3}{ }^{-}\right)$ & $\mathrm{mg} \mathrm{L}^{1}$ & 88,4 \\
Cloreto $\left(\mathrm{Cl}^{-}\right)$ & $\mathrm{mg} \mathrm{L}^{1}$ & 19,0
\end{tabular}




\begin{tabular}{|c|c|c|}
\hline Nitrato $\left(\mathrm{N}-\mathrm{NO}_{3}\right)$ & $\mathrm{mg} \mathrm{L}^{1}$ & 0,6 \\
\hline Sulfato $\left(\mathrm{SO}_{4}{ }^{2-}\right)$ & $\mathrm{mg} \mathrm{L}^{1}$ & 12,1 \\
\hline Fósforo (P) & $\mathrm{mg} \mathrm{L}^{1}$ & 0,14 \\
\hline Nitrogênio Amoniacal $\left(\mathrm{N}-\mathrm{NH}_{3}\right)$ & $\operatorname{mg~} \mathrm{L}^{1}$ & 1,1 \\
\hline Sódio $\left(\mathrm{Na}^{+}\right)$ & $\mathrm{mg} \mathrm{L}^{1}$ & 24,0 \\
\hline Potássio $\left(\mathrm{K}^{+}\right)$ & $\mathrm{mg} \mathrm{L}^{1}$ & 6,3 \\
\hline Cálcio $\left(\mathrm{Ca}^{2+}\right)$ & $\operatorname{mg~} \mathrm{L}^{1}$ & 17,5 \\
\hline Magnésio $\left(\mathrm{Mg}^{2+}\right)$ & $\operatorname{mg} L^{1}$ & 3,7 \\
\hline Ferro $\left(\mathrm{Fe}^{2+}\right)$ & $\operatorname{mg} \mathrm{L}^{1}$ & 0,75 \\
\hline Cobre $\left(\mathrm{Cu}^{2+}\right)$ & $\operatorname{mg~} L^{1}$ & 0 \\
\hline Manganês $\left(\mathrm{Mn}^{2+}\right)$ & $\operatorname{mg} \mathrm{L}^{1}$ & 0,04 \\
\hline Zinco $\left(\mathrm{Zn}^{2+}\right)$ & $\operatorname{mg~L}{ }^{1}$ & 0,17 \\
\hline Cor Aparente & $\mathrm{mg} \mathrm{L}^{1}$ & 230 \\
\hline Turbidez & $\operatorname{mg~} \mathrm{L}^{1}$ & 48 \\
\hline Sedimentos em suspensão & PtCo & 25 \\
\hline Condutividade elétrica (CE) & $\mathrm{dS} \mathrm{m}^{-1}$ & 0,18 \\
\hline $\mathrm{pH}$ & $\operatorname{mg~} \mathrm{L}^{1}$ & 7,4 \\
\hline Gás Carbônico $\left(\mathrm{CO}_{2}\right)$ & $\mathrm{mS} \mathrm{cm}^{-1}$ & 5,3 \\
\hline Acidez $\left(\mathrm{CaCO}_{3}\right)$ & --- & 33 \\
\hline Dureza Total* $\left(\mathrm{CaCO}_{3}\right)$ & $\mathrm{mg} \mathrm{L}^{1}$ & 58,7 \\
\hline Coliformes totais/100mL & $\mathrm{mg} \mathrm{L}^{1}$ & $1,3 \times 10^{3}$ \\
\hline Coliformes termotolerantes/100mL & $\operatorname{mg~L}^{1}$ & $9,2 \times 10^{2}$ \\
\hline
\end{tabular}

*Dureza Total calculado com base no equivalente de Carbonato de cálcio $\left(\mathrm{CaCO}_{3}\right)$ segundo Franson (1995): 2,497 [Ca, $\left.\mathrm{mg} \mathrm{L}^{-1}\right]+4,118\left[\mathrm{Mg}, \mathrm{mg} \mathrm{L}^{-1}\right]$

Durante o ensaio foram mantidos os espaçamentos originais das linhas gotejadoras, com o objetivo de evitar diferenças relacionadas à influência de emendas e da proximidade dos emissores, reduzindo os erros e mantendo, assim, as mesmas condições das linhas utilizadas pelos irrigantes. Desta forma o número de gotejadores presentes na linha dependeu do espaçamento fornecido pelo fabricante, porém foi assegurado um número mínimo de 10 emissores para cada modelo analisado.
A Tabela 4 apresenta os emissores com suas características técnicas, ensaiados nas Fases 1 e 2 . Em função dos emissores ensaiados serem produtos comerciais e os ensaios a que foram submetidos não serem normatizados, os dados e análises realizados em todos os ensaios foram codificados para evitar qualquer tipo de especulação comercial dos resultados apresentados. A codificação utilizada na representação dos modelos de emissores, não tem nenhuma relação 
com os nomes comerciais dos produtos

emissores apresentados na Tabela 4. e nem tampouco com a sequência de

Tabela 4. Características técnicas: fluxo, vazão, diâmetro nominal ( $\varnothing \mathrm{N})$ e espaçamento entre gotejadores dos modelos convencionais utilizados no experimento das Fases 1 e 2

\begin{tabular}{cccccc}
\hline Fabricante & Modelo & Fluxo & ${\text { Vazão }\left(\mathrm{L} \mathrm{h}^{-1}\right)}$ & $\varnothing \mathrm{N}(\mathrm{m})$ & Espaçamento $^{1}(\mathrm{~m})$ \\
\hline \multirow{3}{*}{ Netafim } & Ram & AC & 2,3 & 16 & 0,50 \\
& Uniram & AC & 1,6 & 16 & 0,33 \\
& Dripnet & AC & 1,6 & 16 & 0,75 \\
\hline \multirow{2}{*}{ Toro Ag } & Drip In & AC & 2,5 & 17 & 0,75 \\
\hline \multirow{3}{*}{ Plastro } & Hydro PC & AC & 2,2 & 17 & 0,80 \\
& Hidro Drip & AC & 2,0 & 16 & 0,80 \\
\multirow{3}{*}{ Irrimon } & Twin Plus & AC & 1,8 & 17,5 & 1,00 \\
& Vip Line & AC & 3,6 & 16 & 1,00 \\
& Irriloc & AC & 1,1 & 16,4 & 0,40 \\
\hline
\end{tabular}

*Autocompensante (AC). Fonte: Catálogo dos fabricantes. ${ }^{1}$ Espaçamento entre gotejadores.

Depois de tabulados os dados, procederam-se os cálculos da vazão, coeficiente de uniformidade de distribuição e do coeficiente de variação de vazão, através das Equações de 1 a 3.

$$
q=\frac{P}{1000 t d} 60
$$

em que:

$\mathrm{q}$ - vazão do gotejador, $\mathrm{L} \mathrm{h}^{-1}$;

$\mathrm{P}$ - peso da água coletada, g;

$\mathrm{t}$ - tempo de coleta, min e

$d$ - densidade da água utilizada no ensaio, g $\mathrm{L}^{-1}$ (o valor médio utilizado para conversão da água para $25{ }^{\circ} \mathrm{C}$, foi de 0,997).

$$
U D=\frac{q_{25 \%}}{q_{m}}
$$

em que:

UD - uniformidade de distribuição (\%);

\section{RESULTADOS E DISCUSSÃO}

$\mathrm{Na}$ Figura 1 encontra-se a uniformidade de distribuição (UD) dos gotejadores autocompensantes utilizados durante todo o período do ensaio, no $q_{25 \%}$ - vazão média dos 25\% menores valores de vazão observada $\left(\mathrm{L} \mathrm{h}^{-1}\right) \mathrm{e}$ $q_{m}$ - média de todas as vazões $\left(\mathrm{L} \mathrm{h}^{-1}\right)$.

$$
C V_{f}=\frac{\sigma}{q_{m}} 100
$$

em que:

$C V_{f}$ - coeficiente de variação de fabricação (\%);

$\sigma-$ desvio padrão da vazão média do emissor $\left(L h^{-1}\right)$ e

$q_{m}$ - vazão média a determinada pressão e temperatura padrão $\left(\mathrm{L} \mathrm{h}^{-1}\right)$.

Os modelos de tubo gotejador foram comparados, conforme o seu desempenho levando em consideração para o coeficiente de uniformidade de distribuição a classificação proposta por Bralts (1986) e para o coeficiente de variação de vazão a classificação proposta por ABNT (2006).

tratamento com: água LAG/6 $\mathrm{mg}$ $\mathrm{L}^{-1}$ de $\mathrm{Fe}^{2+}$ (sulfato ferroso) (fase 1); água $\mathrm{LAG} / 18,8 \mathrm{mg} \mathrm{L}^{-1}$ de $\mathrm{Fe}^{2+}$ (sulfato ferroso, óxido de ferro e hidróxido de ferro)/emissor $\downarrow /$ sólidos suspensos (fase 2). 


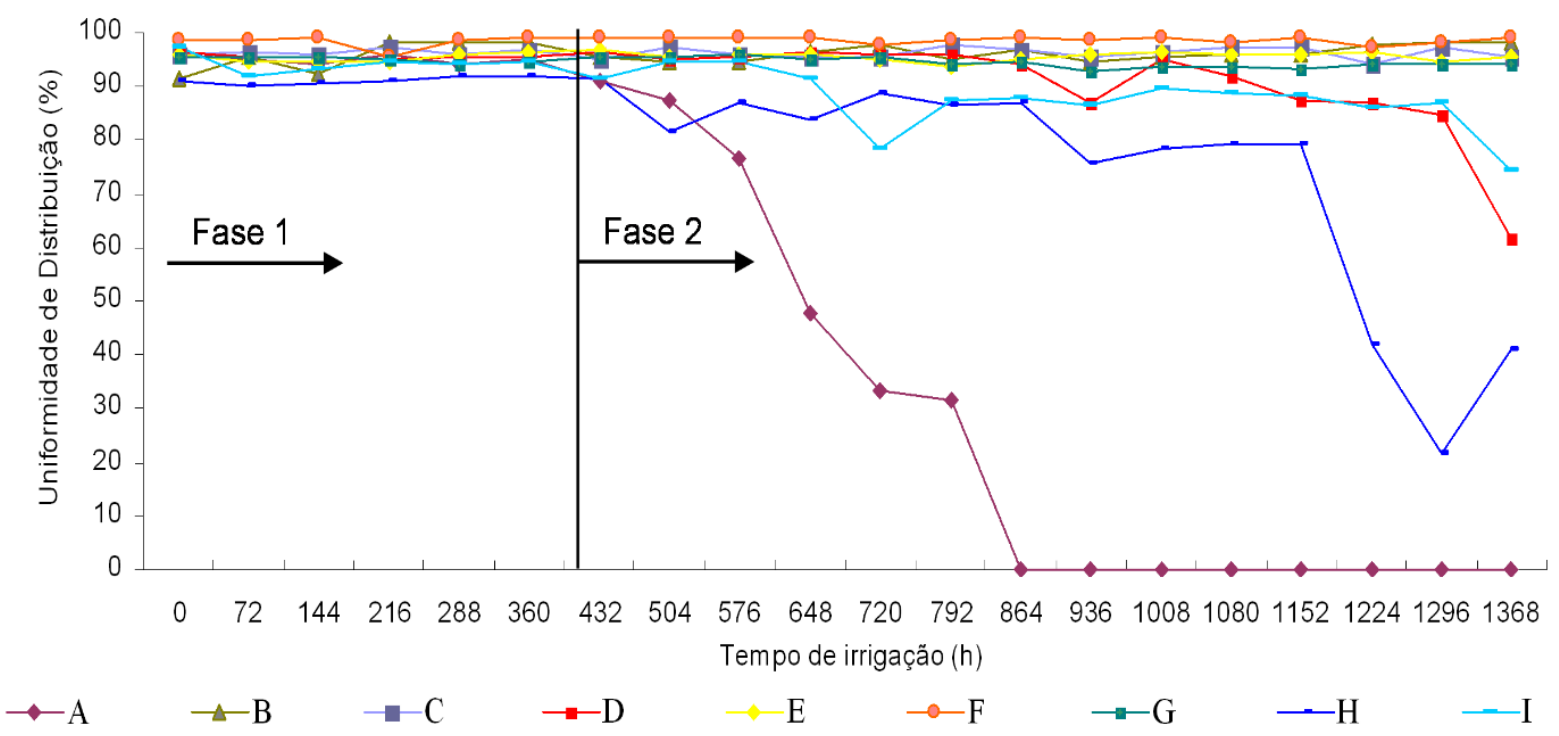

Figura 1. Uniformidade de Distribuição (\%) dos gotejadores autocompensantes T3 - F1/água LAG/6 $\mathrm{mg} \mathrm{L}^{-1}$ de $\mathrm{Fe}^{2+}$ (sulfato ferroso) e no T3 - F2/água LAG/18,8 $\mathrm{mg} \mathrm{L}^{-1}$ de Fe $\mathrm{Fe}^{2+}$ (sulfato ferroso, óxido de ferro e hidróxido de ferro)/emissor $\downarrow$ /sólidos suspensos.

A uniformidade na fase 1 para os modelos de tubo gotejadores D e I, na fase 1 , a 0 horas de funcionamento apresentaram a uniformidade máxima de 96,5 e 97,2\% e mínima de 91,3 e 95,8\% para os modelos de tubo gotejadores $\mathrm{B}$ e $\mathrm{C}$, respectivamente. Já para os modelos de tubo gotejadores A, B, C, E, F, G e $\mathrm{H}$ a uniformidade máxima na fase 1 foi de 96,1, 98,3, 97,2, 96,6, 99,3, 95,6 e 92,1\% as $216,360,216,360,144,144$ e 360 horas de funcionamento, respectivamente, à medida que para os modelos de tubo gotejadores A, D, E, F, G, H e I a uniformidade mínima foi de 94, 95, 94,4, $95,5,94,2,90,92,1 \%$ as $288,216,72,216$, 288, 72 e 72 horas de funcionamento, respectivamente. Constata-se deste modo que a diferença entre a máxima e mínima uniformidade não ultrapassou os $7 \%$.

Os modelos de tubo gotejadores $\mathrm{B}$, $\mathrm{C}, \mathrm{E}, \mathrm{F}$ e $\mathrm{H}$ mostraram decréscimos na uniformidade de $7,1,0,5,0,4$ e $1 \%$ respectivamente, enquanto o modelos $\mathrm{A}$, D, G e I apresentaram acréscimos na uniformidade de distribuição de 0,9, 1,2, 0,6 e $2,7 \%$, respectivamente (fase 1 ), quando comparado as 0 horas com as 360 horas de funcionamento.

A partir da Fase 2, pode-se observar reduções mais expressivas na uniformidade de distribuição. O modelo de tubo gotejador $\mathrm{A}$ aos $432 \mathrm{~h}$ de funcionamento apresentou uma diminuição média na uniformidade de $3,7 \%$, com relação as 360 e 504 h de funcionamento respectivamente. Já as 576, 648 e 720 h de funcionamento ocorre quedas mais expressivas na uniformidade de um período de funcionamento para o outro, sendo estas de aproximadamente 11, 29 e $14 \%$ respectivamente, seguido de uma estabilização na uniformidade ocorrida entre as 720 e $792 \mathrm{~h}$ de funcionamento e em subsequência ao entupimento parcial a ocorrência do entupimento total, com uma redução na uniformidade de 31,4\%, o que é bastante característico ao entupimento total, após diminuições progressivas e alguma estabilização a ocorrência do entupimento total ocorre geralmente de maneira súbita.

$\mathrm{O}$ modelo de tubo gotejador $\mathrm{H}$ das 432 às $864 \mathrm{~h}$ de funcionamento apresentou uma uniformidade média de $86,5 \%$, sendo 
está classificada como boa conforme classificação proposta por Bralts (1986), entretanto das 936 às $1152 \mathrm{~h}$ de funcionamento a uniformidade foi considerada como regular e entre as $1224 \mathrm{e}$ 1368 h de funcionamento a uniformidade de distribuição como ruim ( $<70 \%)$, apenas o modelo de tubo gotejador $\mathrm{D}$ às $1368 \mathrm{~h}$ de funcionamento também não mostrou um comportamento muito satisfatório, com uma uniformidade de $61,6 \%$ a qual segundo a mesma classificação é considerada ruim.

O modelo de tubo gotejador I de forma semelhante ao modelo de tubo gotejador D às $1368 \mathrm{~h}$ de funcionamento, demonstrou sua menor uniformidade de distribuição, sendo esta de 74,3\%, a qual é classificada como regular. Para Busato et al. (2010) verificaram que após $700 \mathrm{~h}$ de funcionamento o modelo M1 apresentou reduções nos valores de Coeficiente de
Uniformidade Estatístico e vazão de 28,35 e 26,1\%, respectivamente; o modelo M2 apresentou reduções de 16,25 e 27,4\%, respectivamente; para o modelo M3, a redução foi de $12,5 \%$ no valor do Coeficiente de Uniformidade Estatístico, tendo apresentado um incremento de $1 \%$ em sua vazão.

Os modelos de tubo gotejador B, C, E, F e $\mathrm{G}$ tiveram os melhores desempenhos na Fase 2, com uniformidade de distribuição classificada como excelente (> $90 \%$ ), com destaque para os modelos de tubo gotejador $\mathrm{B}$ e $\mathrm{F}$, com uma uniformidade de distribuição próxima de $100 \%$.

Na Figura 2 encontram-se o coeficiente de variação (CV), no período do ensaio, para os modelos de gotejadores autocompensantes avaliados durante todo o período

ensaio.

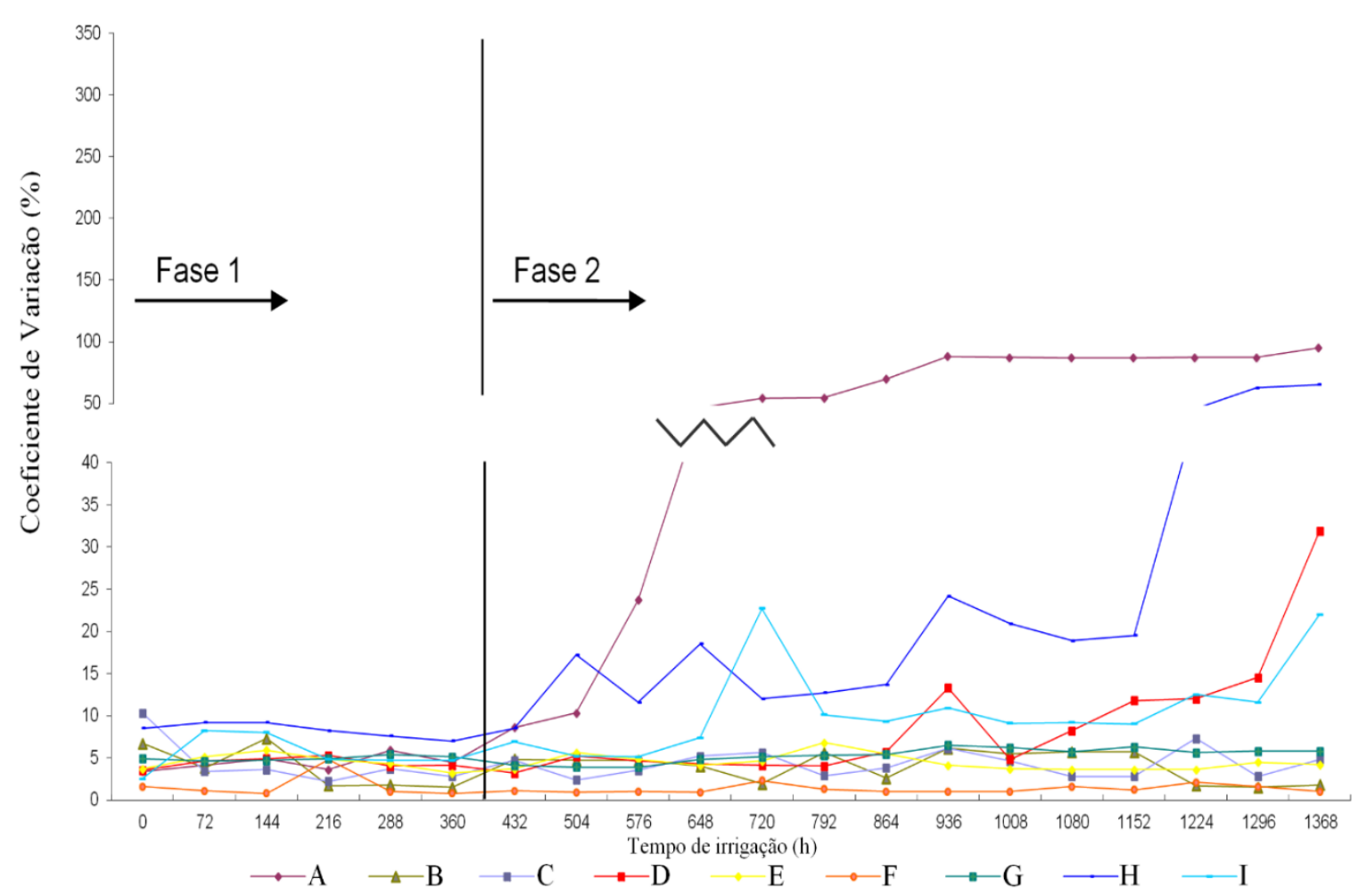

Figura 2. Coeficiente de variação de vazão (\%) de todos os gotejadores autocompensantes avaliados, no período do ensaio, no Tratamento T3 - F1/água LAG/6 $\mathrm{mg} \mathrm{L}^{-1}$ de $\mathrm{Fe}^{2+}$ (sulfato ferroso) e no T3 F2/água LAG/18,8 $\mathrm{mg} \mathrm{L}^{-1}$ de $\mathrm{Fe}^{2+}$ (sulfato ferroso, óxido de ferro e hidróxido de ferro)/emissor $\downarrow /$ sólidos suspensos.

Os modelos de tubo gotejador A, B, C, D, E, F, G e H na Fase 1, mostraram coeficiente de variação (CV) máximo de $5,9,7,3,10,5,3,5,9,4,8,5,4,9,2$ e 8,2\% ás 
288, 144, 0, 216, 144, 216, 288, 72 е 72 horas de funcionamento respectivamente; assim de maneira geral na Fase 1 os emissores avaliados apresentaram coeficiente de variação de vazão $(<10 \%)$, sendo, portanto, considerados bons de acordo com a classificação da ABNT (2006).

Os modelos de tubo gotejador $\mathrm{A}$ e $\mathrm{H}$ na Fase 2, apresentaram CV maiores que $10 \%$ desde às $504 \mathrm{~h}$ de funcionamento, e alcançando um CV máximo de 94,9 e $65,2 \%$ às $1368 \mathrm{~h}$ de funcionamento, respectivamente. Teixeira (2006), trabalhando com efeitos de dosagens extremas de cloro e $\mathrm{pH}$ na vazão de gotejadores autocompensantes observou que em alguns modelos de tubos gotejadores autocompensantes houve uma tendência de acréscimo nos valores de CV ao longo do experimento, aonde chegaram a um aumento de $185 \%$ e de $220 \%$ no valor de CV em relação ao CV inicial. Os modelos de tubo gotejador De I também apresentaram valores de CV altos às 1368 $\mathrm{h}$ de funcionamento, sendo estes de aproximadamente $\quad 32$ e $\quad 22 \%$ respectivamente.

Os modelos de tubo gotejador $\mathrm{B}, \mathrm{C}$, E, F e G demonstraram CV máximo de 6,1, 7,3, 6,8, 2,3 e 6,5\% ás 936, 1224, 792, 720, e 936 horas de funcionamento respectivamente, consequentemente como na Fase 1, também na Fase 2 esses emissores avaliados apresentaram coeficiente de variação de vazão ( $<10 \%)$, sendo, portanto, considerados bons de acordo com a classificação da ABNT (2006).

\section{CONCLUSÕES}

Nos ensaios realizados o modelo $\mathrm{E}$ foi $o$ que apresentou a melhor uniformidade de aplicação.

$\mathrm{O}$ tratamento realizado no experimento mostrou que o modelo de emissor I foi o que sofreu maior percentual de obstrução.

A uniformidade de aplicação foi afetada pela aplicação $\mathrm{Fe}^{+2}$ causando alterações de forma gradativa, as quais tendem aumentar com o tempo de aplicação.

\section{AGRADECIMENTOS}

Os autores agradecem ao Ministério da Ciência e Tecnologia (MCT), ao Conselho Nacional de Desenvolvimento Científico e Tecnológico (CNPq) e à Coordenação de Aperfeiçoamento de Pessoal de Nível Superior (Capes).

\section{REFERÊNCIAS BIBLIOGRÁFICAS}

ABNT - Associação Brasileira de Normas Técnicas. Equipamentos de irrigação agrícola - Emissores e tubos emissores Especificações e métodos de ensaio. ABNT NBR ISO 9261, 2006. 9p.

BRALTS, V.F. Field performance and evaluation. In: NAKAYAMA, F.S.; BUCKS, D.A. (Ed.) Trickle irrigation for crop production. Amsterdam: Elsevier, 1986. p.216-240.

BUSATO, C. C. M.; SOARES, A. A. Desempenho de gotejadores, utilizando água de baixa qualidade química e biológica. Biosci. J., Uberlândia, v. 26, n. 5, p. 739-746. 2010.

BUCKS, D.A.; NAKAYAMA, F.S.; GILBERT, R.G. Trickle irrigation water quality and preventive maintenance. Agricultural Water Management, Amsterdam, v. 2, p. 149-162, 1979.

CAPRA, A.; SCICOLONE, B. Emitter and filter tests for wastewater reuse by drip irrigation. Agricultural Water Management, Amsterdam, v. 68, n. 2, p. 135- 149, 2004. 
COELHO, R. D.; TEIXEIRA, M. B.; CARVALHO, L. C. C.; CUNHA, F. C.; SILVA, N. F. Distúrbios de vazão em gotejadores devido o uso de água com presença de ferro. Revista Brasileira de Agricultura Irrigada, v.8, $n^{\circ} .3$, p. 234 246, 2014.

COELHO, R.D. Contribuições para a irrigação pressurizada no Brasil. 2007. 192 p. Tese (Livre-Docência) - Escola Superior de Agricultura "Luiz de Queiroz", Universidade de São Paulo, Piracicaba, 2007.

COSTA, C. C.; CAMPOS, C. M. M.; FARIA, M. A. Vulnerabilidade de tubos gotejadores ao entupimento por precipitados químicos de ferro. Revista agrogeoambiental, v. 2, n. 1, p. 18-27, 2010.

CUNHA, F. N.; OLIVEIRA, R. C.; SILVA, N. F.; MOURA, L. M. F.; TEIXEIRA, M. B.; GOMES FILHO, R. R. Variabilidade temporal da uniformidade de distribuição em sistema de gotejamento.

Revista Brasileira de Agricultura Irrigada, v.7, n. 4, p. 248 - 257, 2013.

GILBERT, R.G.; NAKAYAMA, F.S.; BUCKS, D.A.; FRENCH, O.F.; ADAMSON, K.C. Trickle irrigation: emitter clogging and flow problems. Agricultural Water Management, Amsterdam, v. 3, p. 159, 1981.
MARTINKO, J.; JOHN, M.; PACK, J. Biology of microorganisms. A Viacom Company Upper Saddle River, New Jersey. 1997.

RAVINA, I.; PAZ, E.; SOFER, Z.; MARCU, A.; SCHISCHA, A.; SAGI, G. Control of emitter clogging in drip irrigation with reclaimed wastewater. Irrigation Science, New York, v. 13, p. 129-139, 1992.

RIBEIRO, P. A. A.; TEIXEIRA, M. B.; COELHO, R. D.; FRANCO, E. M.; SILVA, N. F.; CARVALHO, L. C. C.; ALVES, M. E. B. Gotejadores submetidos a condições críticas de qualidade da água. Brazilian Journal of Irrigation and Drainage, Botucatu, Ed. Especial, p. 368 379, 2012.

SAGI, G.; PAZ, E.; RAVINA, I. Clogging of drip irrigation systems by colonial protozoa and sulphur bacteria. In: INTERNATIONAL

MICROIRRIGATION CONGRESS, 5., 1995, Orlando. Proceedings... St. Joseph: ASAE, 1995. p. 250-254.

TEIXEIRA, M.B. Efeitos de dosagens extremas de cloro e $\mathbf{p H}$ na vazão de gotejadores autocompensantes (irrigação localizada). 2006. 322 p. Tese (Doutorado em Irrigação e Drenagem) Escola Superior de Agricultura "Luiz de Queiroz”, Universidade de São Paulo. Piracicaba, 2006. 